\title{
Tyre rolling resistance and its influence on fuel consumption
}

Rolling resistance of tyres is one of the major resistive forces acting on any wheeled vehicle. Unfortunately, it is also one of the forces very difficult to measure. It is estimated that in certain traffic conditions (like for example constant speed driving with slow or moderate speed) so called Rolling Resistance Impact Factor may be as high as 0.3. This means that reduction of rolling resistance by $50 \%$ would lead to $15 \%$ of energy savings. The paper presents road measuring method of tyre rolling resistance and unique equipment used by the Technical University of Gdańsk designed to perform measurements of passenger car tyres. It also discusses road pavement, tyre and environmental conditions influence on rolling resistance. Also selected data describing current situation related to rolling resistance on different road pavements and rolling resistance of modern passenger car tyres including tyres specially designed for electric and hybrid vehicles are presented.

Key words: tyres, measuring methods, rolling resistance, fuel consumption, $\mathrm{CO}_{2}$ emission

\section{Introduction}

In order to move every vehicle must overcome resistive forces acting on it. Those forces are controlling the vehicle's performance and energy consumption. Lower value of resistance means better acceleration, higher speed and lower energy consumption leading to longer range and less costly operation of the vehicle.

Generally speaking, several resistive forces act or may act on a moving car. They are shown in Fig. 1. Some of the forces act on the vehicle all the time (rolling resistance, drag) some of them may not be present in a certain driving condition (inertia forces, up/downhill force, tow force).

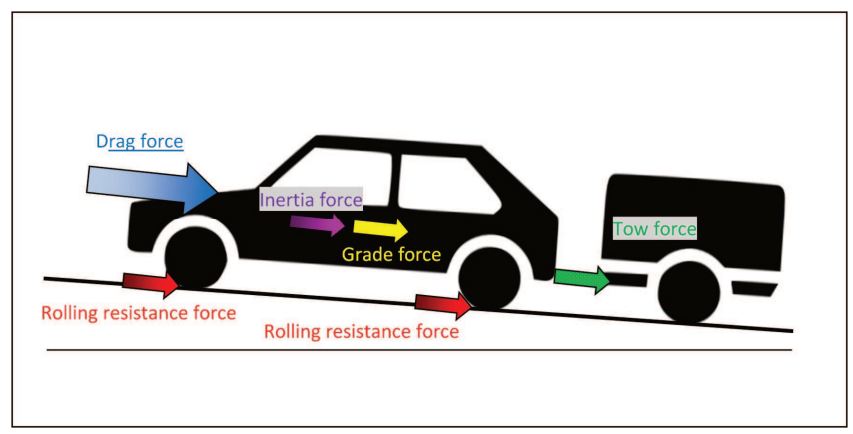

Fig. 1. Resistive forces acting on moving car

For different traffic conditions relative influence of the resistive forces may be very different. For example during driving in congested traffic the inertia force tends to dominate over other forces with rolling resistance force being the second important. During uninterrupted suburban driving with low or moderate speeds rolling resistance clearly dominates with aerodynamic drag force being the second, while at highway speeds it is the contrary. In mountain areas both grade and inertia forces may dominate other resistive forces.

This paper presents problems related to influence of tyre rolling resistance on overall energy (fuel) consumption and problems related to measuring of rolling resistance force which is one of the most complicated to measure parameter of tyre/road interface.

\section{Rolling resistance force}

Tyre rolling resistance $\left(\mathrm{F}_{\mathrm{R}}\right)$ is the force resisting the motion of the tyre when it rolls on a road surface. It is mainly caused by non-elastic effects in tyre and slippage between the tyre tread and the pavement, which leads to dissipation of energy. Contrary to early diagonal tyres, rolling resistance of modern radial car tyres is not very much dependent on the speed (see Fig. 2), therefore for basic modeling used in this report it was assumed that rolling resistance is constant within low and moderates speed range and given by the equation (1).

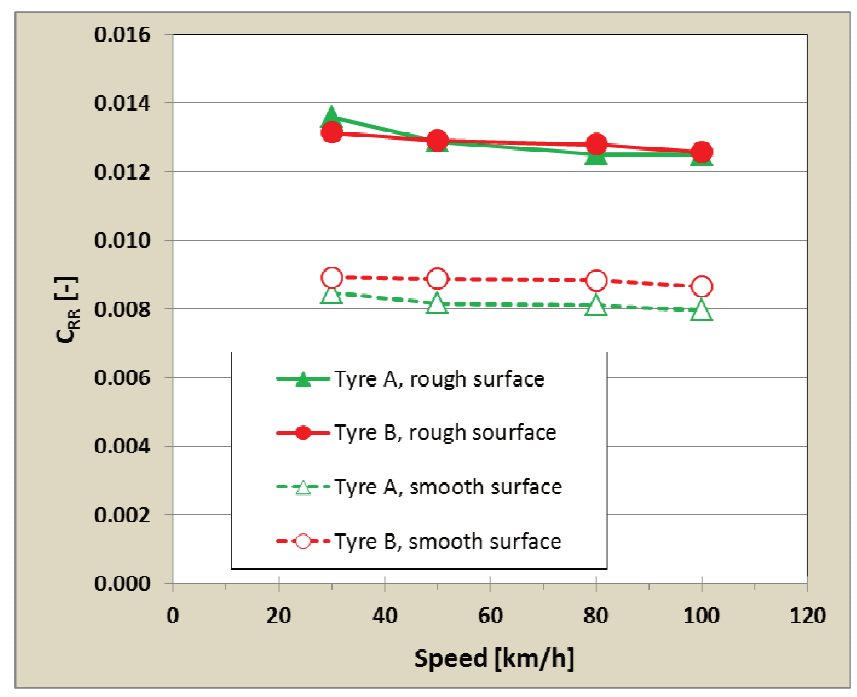

Fig. 2. Speed influence on tyre rolling resistance (results of laboratory measurements performed according to ISO standard)

$$
\mathrm{F}_{\mathrm{R}}=\mathrm{C}_{\mathrm{RR}} * \mathrm{~F}_{\mathrm{L}}
$$

where: $F_{R}$ - force of rolling resistance $[N], C_{R R}-$ coefficient of rolling resistance [-], $\mathrm{F}_{\mathrm{L}}-$ vertical load [N].

Rolling resistance depends on many factors related to road, tyre, and operating conditions. Most important influences of the road are: pavement texture, road unevenness and road stiffness. Most important influences of the tyre are: tyre size, rubber hysteresis, rubber hardness, construc- 
tion of the belt and carcass, tread pattern and tread depths. Many operating conditions also influence tyre rolling resistance, especially: inflation pressure, air and pavement temperature, pavement wetness and tyre load.

\section{Measuring methods of rolling resistance}

\subsection{General remarks}

Tyre rolling resistance is very difficult to measure because it constitutes roughly only $1 \%$ of vertical force acting on the tyre. If desired accuracy is also $1 \%$, for typical passenger car tyre loaded to $4000 \mathrm{~N}$ it is necessary to precisely measure forces in the range of $40 \mathrm{~N}$ with accuracy at least $0.4 \mathrm{~N}$. This task which is difficult even in the laboratory conditions becomes extremely difficult in road conditions when many important variables are less controlled.

As an example of the problems it may be mentioned that if the vertical force loading the test tyre via force sensor is not exactly vertical but it is tilted by 20 seconds of angle the resulting measuring error is at about $1 \%$ of evaluated rolling resistance force - see Fig. 3 .

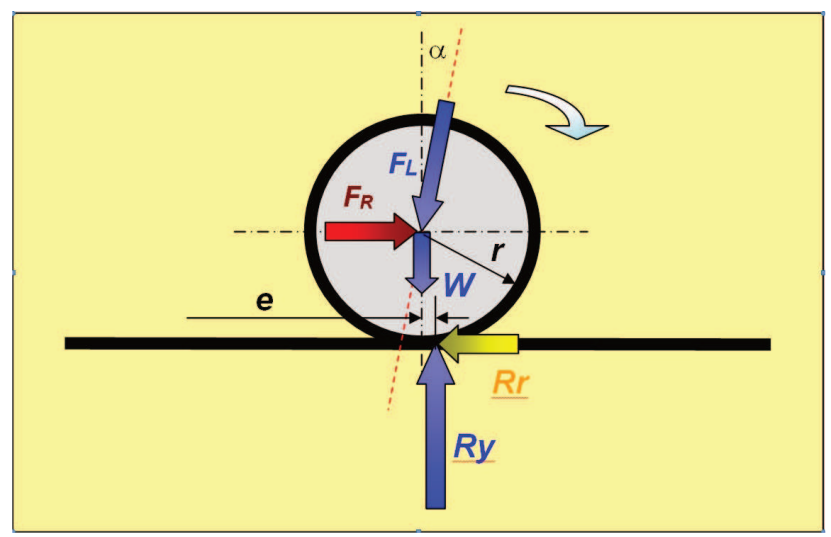

Fig. 3. Influence of imperfections in measuring system on accuracy of rolling resistance measurements

What is more, tyre rolling resistance is very sensitive to tyre inflation pressure and load [1], surface wetness [2] and temperature [3]. All those variables must be thoughtfully controlled during measurements and if it is not possible to control them (like for example temperature during road measurements), certain corrections must be applied.

\subsection{Laboratory methods}

Laboratory methods are based on so called "roadwheal facilities" which are big drums acting as "moving road" for tyres. One of the drum facilities used at the Technical University of Gdańsk is shown in Fig. 4.

General advantages of using drum facilities for rolling resistance measurements are as follows:

- measurements may be carried indoor with full control of ambient conditions,

- measurements are not biased by the driving style,

- easy adjustment of measuring conditions (load, inflation pressure, speed),

- low cost of measurements.

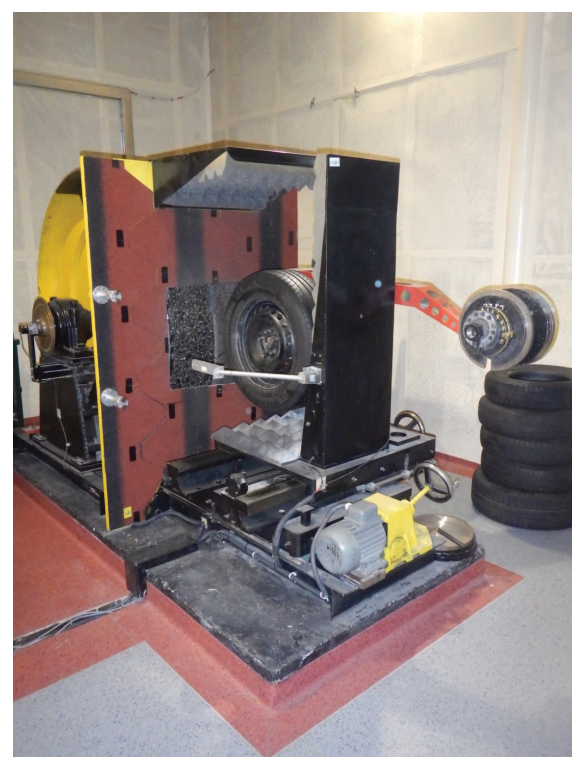

Fig. 4. Roadwheel facility with $1.7 \mathrm{~m}$ diameter drum at the Technical University of Gdansk, Poland

Unfortunately there is a lot of problems related to the use of drums for rolling resistance measurements. Most important ones are listed below:

- road surface interfacing the test tyre is not flat but has certain curvature,

- there are serious problems with obtaining representative texture of the road pavement and special replica road surfaces must be manufactured,

- tyres have tendency to worn replica road surfaces and deposit rubber particles on them as there is no natural cleaning provided by changing weather conditions.

There are three commonly used laboratory methods of rolling resistance measurements, namely Force Method, Torque Method and Deceleration Method. All three roadwheel facilities at the Technical University of Gdańsk use torque method.

\subsection{Road methods}

Road methods are not so popular as laboratory methods because they are very difficult to carry out. Road methods are best suited for investigation of road surface influence on tyre rolling resistance. The most important advantages are:

- tyres roll on real road pavements so the phenomena related to the tyre/road interfacing are not distorted,

- road surface is flat so interaction between tyre and pavement is not impaired.

Despite very important benefits there are lots of problems related to the road methods. Most important ones are listed below:

- during measurements ambient conditions are difficult to control,

- there are a lot of sources of measurement errors like wind, road grade or acceleration/deceleration,

- performing measurements is time consuming and/or measuring equipment is very expensive,

- for some road methods it is not possible to make measurements on trafficked roads,

Road measurements may be performed using ordinary cars or trucks (sometimes with special conversions) or by 
utilizing specially build trailers [4]. In contrast to the laboratory methods there is not a single standard regulating road measurements of the rolling resistance.

There are four basic road methods that may be performed with the use of ordinary vehicles [5]. The methods are:

- Coast Down Method,

- Power Train Torque Method,

- Fuel Consumption Method,

- Trailer Method.

Trailer method of rolling resistance measurements is the most versatile method and at the same time the most difficult one. At present there are only five known trailers that may make accurate measurements of rolling resistance of passenger car tyres. Two of them were built and are used by the Technical University of Gdańsk. One of the trailers called $\mathrm{R}^{2}$ Mk.2 is generally considered to be the most advanced and most versatile on the world. The trailer is described in [6] and presented in Fig. 5 and 6. It makes measurements both in EU countries and in the USA [7].

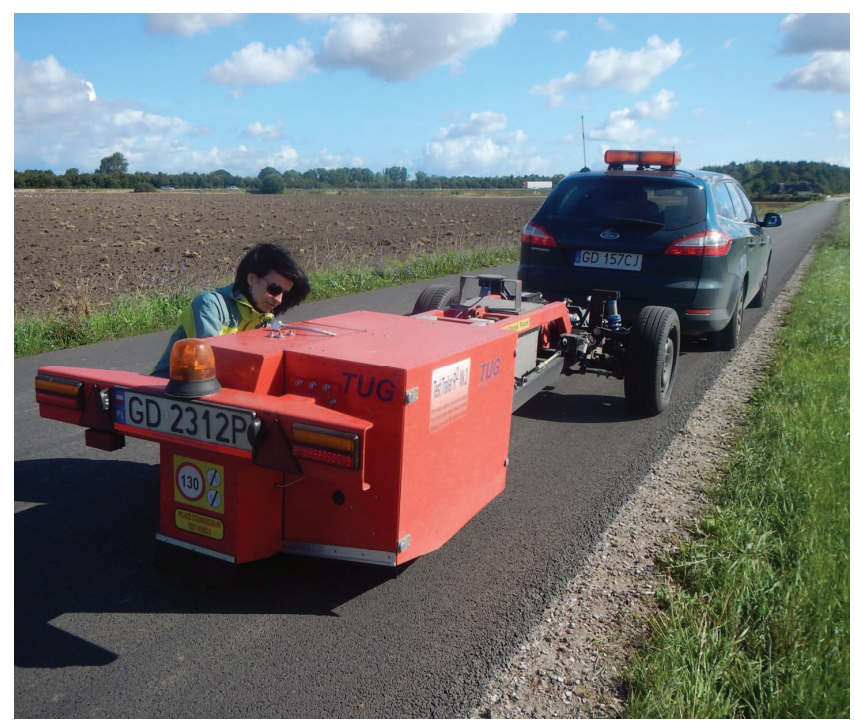

Fig. 5. Test trailer R2 Mk.2 built by the Technical University of Gdańsk



Fig. 6. Interior of the test trailer $\mathrm{R}^{2} \mathrm{Mk} .2$

\subsection{Rolling resistance coefficients for modern tyres and road pavements}

In open literature most of the data related to tyre rolling resistance originate from measurements made on steel drums that are not representative for road conditions or measurements performed a long time ago by the coast down method. What is more, a few years ago a new concept of passenger car tyres was developed, namely "Blue Tyres" designed for electric and hybrid vehicles.

With a few exceptions most of the electric cars are developed for urban and suburban driving conditions where maximal speeds are rather restricted and high speed handling or tractions do not play a leading role in tyre ranking. For electric cars, especially low end and medium class it is however very important to ascertain as long operational range as possible because a typical electric car has only $120-150 \mathrm{~km}$ range. Adding 20-30 km of range to such a car due to low rolling resistance tyres may make remarkable difference for the driver.

It is interesting to note that, in fact there are two different "families" of tyres design for electric cars. First family has tyres that have similar sizes to tyres for conventional cars with internal combustion engines and the second family is composed with tyres developed for electric vehicles constructed in nonorthodox way. Those tyres have usually got very narrow tread and very big rim diameter - see Fig. 7.



Fig. 7. Tyres for electric cars; on the left - tyre of typical size for modern cars with conventional design, on the right - tyre for electric cars constructed in nonorthodox way

All results reported in this paper were obtained by using $\mathrm{R}^{2}$ Mk. 2 test trailer and measuring conditions described as "TUG measuring conditions" that differ slightly from existing ISO standards. At TUG conditions the vertical load acting on the tyre is set to $4000 \mathrm{~N}$, inflation pressure (regulated) is kept at the value of $210 \mathrm{kPa}$ and speed is $80 \mathrm{~km} / \mathrm{h}$. All reported results are corrected to air temperature $20^{\circ} \mathrm{C}$.

Test tyres that were used for experiments are listed in Tab. 1. As there is no ISO standard for rolling resistance measurements on the road, Technical University of Gdańsk introduced several years ago set "informal reference tyres" that was adopted by most of the research institutes worldwide. Two of the tyres in the set (SRTT and AV4) are also used in ISO 11819-3 standard as reference tyres for tyre/road noise measurements. Tyre MCPR was selected as modern market tyre for medium class passenger cars while tyre BLUECO was selected as state of the art tyre specially developed for electric cars. 
Table 1. List of tyres used during experiments

\begin{tabular}{|l|c|c|}
\hline $\begin{array}{c}\text { Tyre desig- } \\
\text { nation }\end{array}$ & Tyre description & Remarks \\
\hline SRTT & $\begin{array}{c}\text { P225/60R16 UNIROYAL Tiger } \\
\text { Paw (Standard Reference Test } \\
\text { Tyre) }\end{array}$ & $\begin{array}{c}\text { Reference tyre } \\
\text { passenger cars. } \\
\text { All-season }\end{array}$ \\
\hline AV4 & 195R14C AVON Super Van \\
AV4 & $\begin{array}{c}\text { Reference tyre for } \\
\text { light trucks }\end{array}$ \\
\hline MCPR & $\begin{array}{c}\text { H25/55R16 MICHELIN Primacy } \\
\text { HP }\end{array}$ & $\begin{array}{c}\text { Informal reference } \\
\text { tyre, summer } \\
\text { tread }\end{array}$ \\
\hline BLUECO & 195/50R18 CONTINENTAL \\
Blueco & $\begin{array}{c}\text { Tyre designed for } \\
\text { electric cars }\end{array}$ \\
\hline
\end{tabular}

In Table 2 selected results of rolling resistance measurements performed during the period 2015-2016 are presented. It is clearly visible, that tyre BLUECO exhibits coefficients of rolling resistance approximately two times smaller than coefficients of other tyres. A similar difference may be attributed also to pavement influence where rolling resistance measured on Surface Dressing 0/14 is about twice as big as rolling resistance on ISO Type DAC 0/6.

Table 2. Coefficients of rolling resistance for selected road surfaces measured at TUG conditions

\begin{tabular}{|l|c|c|c|c|}
\hline \multirow{2}{*}{ Road pavement } & \multicolumn{4}{c|}{ Tyre } \\
\cline { 2 - 5 } & SRTT & AV4 & MCPR & BLUECO \\
\hline $\begin{array}{l}\text { Stone Mastic Asphalt, } \\
\text { SMA11 }\end{array}$ & 0.0086 & 0.0121 & 0.0110 & 0.0068 \\
\hline $\begin{array}{l}\text { Stone Mastic Asphalt, } \\
\text { SMA8 COOEE }\end{array}$ & 0.0084 & 0.0112 & 0.0108 & 0.0064 \\
\hline $\begin{array}{l}\text { Stone Mastic Asphalt, } \\
\text { SMA6 COOEE }\end{array}$ & 0.0078 & 0.0119 & 0.0105 & 0.0059 \\
\hline $\begin{array}{l}\text { Dense Asphalt Concrete, } \\
\text { DAC 12.5 }\end{array}$ & 0.0080 & 0.0121 & 0.0113 & 0.0053 \\
\hline $\begin{array}{l}\text { Surface Dressing, SD } \\
\text { 0/14 }\end{array}$ & 0.0133 & $\mathbf{0 . 0 1 6 1}$ & 0.0160 & 0.0082 \\
\hline $\begin{array}{l}\text { Surface Dressing, SD } \\
\text { 8/10 }\end{array}$ & 0.0111 & 0.0147 & 0.0141 & 0.0074 \\
\hline Fine Surface Dressing, & 0.0068 & 0.0110 & 0.0088 & $\mathbf{0 . 0 0 4 1}$ \\
\hline $\begin{array}{l}\text { Porous Hot Mix Asphalt, } \\
\text { HMA }\end{array}$ & 0.0088 & 0.0132 & 0.0130 & 0.0058 \\
\hline $\begin{array}{l}\text { Portland Cement Con- } \\
\text { crete, PCC Conventional } \\
\text { Diamond Grind }\end{array}$ & 0.0076 & 0.0115 & 0.0109 & 0.0052 \\
\hline ISO Type DAC 0/6 & 0.0069 & 0.0107 & 0.0081 & 0.0045 \\
\hline $\begin{array}{l}\text { Concrete block pavement } \\
\text { (50 km/h) }\end{array}$ & 0.0081 & 0.0116 & 0.0104 & 0.0050 \\
\hline
\end{tabular}

When permutations of tyres and road surfaces are compared the difference between "the best" and "the worst" combinations is even bigger. The best combination of tyre/pavement is marked in Table 1 with green background color and $\mathrm{C}_{\mathrm{RR}}$ for it is as low as 0.0041 while the worst is marked with red color and $C_{R R}$ is as high as 0.0161 . Although both combinations are in some way extreme they show that in principle by playing with road pavements and tyres the rolling resistance may be quadrupled.

There is still ongoing discussion how to describe road surface texture in order to obtain good correlation with tyre rolling resistance. Commonly used Mean Profile Depth (MPD) in opinion of this authors is not appropriate as it treats each part of the texture profile in the same way. During interaction of tyre with pavement very often there is no contact between rubber of the tread and "valleys" of the texture as only summits of protruding aggregate interfaces with tyre. MPD is however calculated also in the areas where contact is not existing and this impairs correlation considerably. The authors believe that it is necessary to base texture estimator on enveloping procedures that account for properties of the tyre tread.

\section{Rolling resistance influence on energy consump- tion}

There are several simulation models used for estimation of energy consumption of light and heavy vehicles. They are usually very complicated and based on numerous input data that can be difficult to obtain. In the case of simulations reported in this paper it was not necessary to use very elaborate models as the goal is not to predict absolute energy consumption values but to evaluate relative changes of energy consumption attributable to rolling resistance changes.

In order to estimate the influence of rolling resistance on energy consumption a very simple mathematical model was created. It was assumed that changes of engine power due to the changes of rolling resistance will not have any influence on engine efficiency at given speed and torque so what follows is that changes of energy (fuel) consumption are proportional to changes of engine power.

The model used for evaluation is based on equations 2 and 3 .

$$
\begin{gathered}
\mathrm{P}=\left(\mathrm{F}_{\mathrm{R}}+\mathrm{F}_{\mathrm{D}}+\mathrm{F}_{\mathrm{I}}+\mathrm{F}_{\mathrm{G}}\right) \cdot \mathrm{V}+\mathrm{P}_{0} \\
\mathrm{E}=\mathrm{P} \cdot \mathrm{t}
\end{gathered}
$$

where: $\mathrm{P}$ - power $[\mathrm{W}], \mathrm{F}_{\mathrm{R}}$ - rolling resistance force $[\mathrm{N}], \mathrm{F}_{\mathrm{D}}$ - drag force $[N], F_{I}$ - inertia force $[N], F_{G}$ - grade force $[\mathrm{N}], \mathrm{V}-$ speed of the vehicle $[\mathrm{m} / \mathrm{s}], \mathrm{E}-$ energy $[\mathrm{J}], \mathrm{P}_{0}-$ during idling $\mathrm{P}_{0}=\mathrm{P}_{\mathrm{i}}$, during normal driving $\mathrm{P}_{0}=\mathrm{P}_{\mathrm{e}}$ (power necessary to rotate unloaded engine) [W].

Basic power necessary to drive a vehicle is calculated according to equation 2. If simulation is performed for conventional vehicle (diesel or petrol engine) the model evaluates when engine braking is present. Most of the vehicles are constructed in such a way that during engine braking fuel consumption is reduced to zero and this behavior is modeled in the algorithm. Algorithm also checks if the speed of vehicle is below $2 \mathrm{~m} / \mathrm{s}$ and if so, the virtual "idling power" value is used $\left(\mathrm{P}_{\mathrm{i}}\right)$. In the case of electric and hybrid vehicles equipped with KERS it is assumed that $50 \%$ of energy during "engine braking" is recovered.

To simplify the calculations, energy is calculated according to equation 3 with time interval of $1 \mathrm{~s}$ and summed for whole driving cycle. During idling fuel consumption for most of conventional cars is at about $0.5-1.41$ of fuel per hour. The authors estimate that virtual "idling power" value $\left(\mathrm{P}_{\mathrm{i}}\right)$ that represents power necessary to idle the engine should be in the range of $0.4-1.3 \mathrm{~kW}$ for typical car engines. To rotate unloaded engine with certain rpm the virtual "rotation power" $\left(\mathrm{P}_{\mathrm{e}}\right)$ is necessary. Estimations shows that depending on rotational speed the value of $P_{e}$ is between $0.5-7.0 \mathrm{~kW}$.

In order to simulate the influence of rolling resistance on overall energy consumption for conventional vehicles, six cars were selected as well as three hybrid cars and one electric car. 
1. 2012 Jeep Liberty

2. 2010 Subaru Outback Wagon

3. 2009 Toyota Corolla

4. 2009 Chevrolet Aveo

5. 2009 GMC Sierra XFE

6. 2010 Ford Mondeo Estate

7. 2011 Chevrolet Volt (HYBRID)

8. 2010 Toyota Prius (HYBRID)

9. 2010 Honda Insight (HYBRID)

10. 2014 SMART (ELECTRIC)

Energy consumption simulations were performed for constant speeds: $30,50,70,90,110,130$ and $150 \mathrm{~km} / \mathrm{h}$ as well as for urban driving cycle FTP 75 . Calculations were performed for rolling resistance coefficients $C_{R R}$ from 0.005 to 0.015 with increment of 0.001 . Rolling resistance coefficient of 0.01 was considered as reference. The energy consumption calculated according to the algorithm does not account for efficiency of the engine and power train but it may be assumed that the efficiency will not change considerably for small and moderate differences in engine load due to changes in rolling resistance. Energy consumption for each rolling resistance coefficient was related to the energy consumption for the same driving conditions but calculated for reference rolling resistance coefficient of $C_{R R}$
$=0.01$. The resulting factor is called in this paper "Relative Change of Energy Consumption" and designated $\mathrm{R}_{\mathrm{E}}$. Values of $\mathrm{R}_{\mathrm{E}}$ obtained for cars with internal combustion engines are presented in Table 3 .

During urban driving the average speed is not high (34 $\mathrm{km} / \mathrm{h}$ ), but a lot of energy is consumed to accelerate vehicles. In conventional cars most of the energy during braking is lost. Also in low-emission vehicles this energy is not fully preserved by energy recovery systems. During urban driving $R_{E}$ for conventional vehicles is on the same level as for constant driving with a constant speed of $110 \mathrm{~km} / \mathrm{h}$. For urban driving a decrease of the rolling resistance coefficient from 0.01 to 0.005 would lead to an $11 \%$ decrease of energy consumption for conventional vehicles.

In order to better describe the influence of rolling resistance on overall energy consumption the authors introduced "Rolling Resistance Impact Factor" (IFRR). This factor shows how much the energy consumption is influenced by a change in rolling resistance coefficient. For example, IFRR $=0.3$ means that decrease of energy consumption will equal $30 \%$ of the decrease of rolling resistance. If the rolling resistance coefficient is reduced from 0.01 to 0.006 the energy consumption will be reduced by: $(0.01-0.006) * 0.3 * 100 \%$, that is $12 \%$. Impact Factors for different vehicles are presented in Table 4.

Table 3. Relative changes of energy consumption for conventional vehicles

\begin{tabular}{|l|l|l|l|l|l|l|l|l|}
\hline \multirow{2}{*}{$\mathrm{C}_{\mathrm{RR}}$} & \multicolumn{9}{|c|}{ Constant speed driving } & \multicolumn{2}{c|}{ FTP-75 } \\
\cline { 2 - 11 } & $30 \mathrm{~km} / \mathrm{h}$ & $50 \mathrm{~km} / \mathrm{h}$ & $70 \mathrm{~km} / \mathrm{h}$ & $90 \mathrm{~km} / \mathrm{h}$ & $110 \mathrm{~km} / \mathrm{h}$ & $130 \mathrm{~km} / \mathrm{h}$ & $150 \mathrm{~km} / \mathrm{h}$ & \\
\hline 0.005 & 0.77 & 0.78 & 0.81 & 0.85 & 0.88 & 0.90 & 0.92 & 0.89 \\
\hline 0.006 & 0.81 & 0.82 & 0.85 & 0.88 & 0.90 & 0.92 & 0.94 & 0.91 \\
\hline 0.007 & 0.86 & 0.87 & 0.89 & 0.91 & 0.93 & 0.94 & 0.95 & 0.93 \\
\hline 0.008 & 0.91 & 0.91 & 0.92 & 0.94 & 0.95 & 0.96 & 0.97 & 0.96 \\
\hline 0.009 & 0.95 & 0.96 & 0.96 & 0.97 & 0.98 & 0.98 & 0.98 & 0.98 \\
\hline 0.010 & 1.00 & 1.00 & 1.00 & 1.00 & 1.00 & 1.00 & 1.00 & 1.00 \\
\hline 0.011 & 1.05 & 1.04 & 1.04 & 1.03 & 1.02 & 1.02 & 1.02 & 1.02 \\
\hline 0.012 & 1.09 & 1.09 & 1.08 & 1.06 & 1.05 & 1.04 & 1.03 & 1.04 \\
\hline 0.013 & 1.14 & 1.13 & 1.11 & 1.09 & 1.07 & 1.06 & 1.05 & 1.07 \\
\hline 0.014 & 1.19 & 1.18 & 1.15 & 1.12 & 1.10 & 1.08 & 1.06 & 1.09 \\
\hline 0.015 & 1.23 & 1.22 & 1.19 & 1.15 & 1.12 & 1.10 & 1.08 & 1.11 \\
\hline
\end{tabular}

Table 4. Rolling Resistance Impact Factor for conventional, hybrid and electric vehicles

\begin{tabular}{|c|c|c|c|c|c|c|c|c|}
\hline \multirow{2}{*}{$\mathrm{C}_{\mathrm{RR}}$} & \multicolumn{7}{|c|}{ Constant speed driving } & \multirow{2}{*}{ FTP-75 } \\
\hline & $30 \mathrm{~km} / \mathrm{h}$ & $50 \mathrm{~km} / \mathrm{h}$ & $70 \mathrm{~km} / \mathrm{h}$ & $90 \mathrm{~km} / \mathrm{h}$ & $110 \mathrm{~km} / \mathrm{h}$ & $130 \mathrm{~km} / \mathrm{h}$ & $150 \mathrm{~km} / \mathrm{h}$ & \\
\hline Conv. & 0.46 & 0.45 & 0.38 & 0.31 & 0.24 & 0.19 & 0.16 & 0.22 \\
\hline Hybrid & 0.42 & 0.43 & 0.38 & 0.31 & 0.25 & 0.21 & 0.17 & 0.32 \\
\hline Electric & 0.35 & 0.36 & 0.31 & 0.25 & 0.20 & 0.16 & 0.13 & 0.31 \\
\hline
\end{tabular}


Generally for all types of cars the highest impact factor is predicted for low end medium speeds. Differences between conventional, hybrid and electric cars are mostly due to different sizes and weight of cars. For example electric car SMART has very low weight comparing to conventional vehicles and rolling resistance is proportional to the weight of the car and this may explain why rolling resistance impact factor for this car is lower.

Analyzing the results presented in Table 4 it is necessary to notice that the model does not account for energy losses due to cornering, or use of electric equipment like air condition, fans, lights. In opinion of this authors it is reasonable to assume that impact factor for slow, constant speed driving (up to $30 \mathrm{~km} / \mathrm{h}$ ) is at about 0.3 while for medium speed driving $(30-90 \mathrm{~km} / \mathrm{h})$ it is at about 0.2 .

\section{Conclusions}

Rolling resistance of car tyres plays a very important role in overall energy (fuel) consumption. This influence is especially essential for slow and medium speed driving. Rolling resistance measurements performed on numerous road pavements and using many modern passenger car tyres indicate that average coefficient of rolling resistance is close to $\mathrm{C}_{\mathrm{RR}}=0.01$. it is however possible to find tyres and road pavements that are responsible for much higher coefficient, as high as $\mathrm{C}_{\mathrm{RR}}=0.016$. This may increase fuel consumption during slow and medium, constant speed driving by $12-18 \%$. On the other hand if special "low rolling resistance" road pavements and tyres designed for electric vehicles ("Blue type") are used it is possible to reduce $C_{R R}$ to 0.004 . Such dramatic reduction of tyre rolling resistance may decrease fuel consumption even by $20 \%$ during slow or medium speed driving.

Tyres designed for electric vehicles may in many cases be also used at conventional cars giving very substantial reduction of costs and emissions toxic gases and $\mathrm{CO}_{2}$.

\section{Acknowledgments}

Research work reported in this article was sponsored by the Polish National Centre for Research and Development (NCBR) within the SPB project ROLRES (Grant Agreement PBS1/A6/1/2012) and Polish-Norwegian Research Programme CORE, project LEO (Grant Agreement 196195/2013).

\section{Bibliography}

[1] EJSMONT, J., TARYMA, S., RONOWSKI, G., ŚWIECZKO-ŻUREK, B. Influence of load and inflation pressure on the tyre rolling resistance. International Journal of Automotive Technology. 2016, 17(2), 237-244.

[2] EJSMONT, J., SJÖGREN, L., ŚWIECZKO-ŻUREK, B. RONOWSKI, G. Influence of road wetness on tirepavement rolling resistance, Journal of Civil Engineering and Architecture. 2015, 9, 1302-1310.

[3] EJSMONT, J., TARYMA, S., RONOWSKI, G., ŚWIECZKO-ŻUREK, B. Influence of temperature on the tyre rolling resistance. International Journal of Automotive Technology. 2017 (accepted for publication).

[4] SANDBERG, U. (editor) Rolling resistance - basic information and state-of-the-art on measurement methods, Deliverable \#1, MIRIAM SP1, 2011.

Beata Świeczko-Żurek, DEng. - Mechanical Faculty at the Technical University of Gdańsk.

e-mail: beazurek@pg.gda.pl

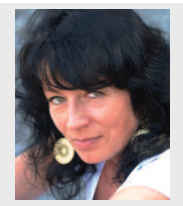

Grzegorz Ronowski, DEng. - Mechanical Faculty at the Technical University of Gdańsk.

e-mail: gronowsk@pg.gda.pl
[5] EJSMONT, J., ŚWIECZKO-ŻUREK, B. Methods of tire rolling resistance measurements. Troisième Congrès $\mathrm{Tu}-$ nisien de Mécanique COTUME'2014, Sousse 24-26 March 2014.

[6] ŚWIECZKO-ŻUREK, B., JASKUŁA, P., EJSMONT, J., KĘDZIERSKA, A., CZAJKOWSKI, P. Rolling resistance and tyre/road noise on rubberised asphalt pavement in Poland. Road Materials and Pavement Design. 18(1), 2017, 151-167.

[7] EJSMONT, J., ŚWIECZKO-ŻUREK, B., RONOWSKI, G., WILDE, J. Rolling resistance measurements at the MnROAD facility. Round 2, Research Project Final Report MN/RC 2014-29, Minnesota Department of Transportation, USA.

Prof. Jerzy Ejsmont, DSc., DEng. - Mechanical Faculty at the Technical University of Gdańsk.

e-mail:jejsmont@pg.gda.pl

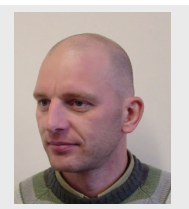

